\title{
Assessment of clinicopathological parameters and outcome of critically ill patients admitted with infectious endemic diseases in a rural tertiary setup of India - An observational study
}

\author{
Anuja P Makan ${ }^{1 *}$, Gajanan Kurundkar ${ }^{2}$
}

${ }^{1}$ Post graduate Resident, ${ }^{2}$ Professor, Department of Medicine, Smt Kashibai Navale Medical College and Hospital, Narhe, Dist. Pune, Maharashtra, INDIA.

Email: makanapoorva@gmail.com

\begin{abstract}
Background: To study the clinico-pathological profile and outcome of critically ill patients with infectious endemic diseases requiring intensive care management Methods: A prospective, non randomized, cross sectional, observational study of 50 critically ill patients (more than 18 years of age) admitted in the ICU setup in a rural tertiary hospital over 2 years, suffering from an endemic tropical disease, was conducted. Parameters to study the outcome of the study were indication for ICU management, evidence of multiple system involvement, common precipitating factor and associated morbidity and mortality. Findings: Our study regarding endemic infectious diseases of Western Maharashtra included 15 females (30\%) and 35 males (70\%). The mean age in our study was $40.52 \pm 15.08$ years with minimum of 19 years and maximum of 63 years. Fever $(n=50)$ followed by jaundice $(n=19)$ and renal failure were the most common presenting features. A qSOFA Score of 2 and 3 were common on presentation $(n=23)$. Mean SOFA score at presentation for patients admitted in the ICU for management of endemic infectious diseases was $13.6 \pm 5.3$. Most common co morbidity seen was diabetes $(n=10)$ followed by thyroid disorders $(n=5)$ and chronic Liver Disease $(n=3)$. Mortality in our study was 12 patients (24\%). Results: It has been seen that higher SOFA scores at 24 hours of presentation led to longer duration of hospital stay. Most common organ failure was renal failure in 29 patients $(28 \%)$ followed by hepatic failure in 17 patients $(34 \%)$ during the course of ICU stay. Conclusion: qSOFA scores of 2 or above at the time of hospitalisation was an important predictor of mortality. Understanding the features and complications of endemic infectious diseases help to identify patients at high risk and treat them with optimal intensive care.
\end{abstract}

Key Words: Endemic, Infectious diseases, qSOFA, ICU stay, Intensive care

*Address for Correspondence:

Dr Anuja P Makan, Resident Hostel 3, Smt.Kashibai Navale Medical College, Narhe, Pune - 411041, INDIA.

Email: makanapoorva@gmail.com

Received Date: 08/07/2020 Revised Date: 14/08/2020 Accepted Date: 02/09/2020

DOI: https://doi.org/10.26611/102116111

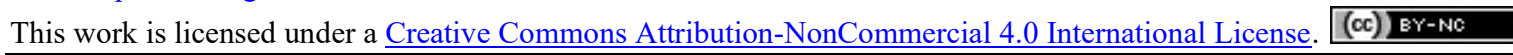

\begin{tabular}{|l|l|}
\hline \multicolumn{2}{|c|}{ Access this article online } \\
\hline Quick Response Code: & Website: \\
& www.medpulse.in \\
& \\
\hline
\end{tabular}

\section{INTRODUCTION}

The word endemic originates from the Greek word enwithin and demos - people or population. Endemic can be defined as "native or confined to a certain region". It refers to a disease that is constantly present to a greater extent in people living in a particular location. ${ }^{1}$ Infectious diseases remain the second leading cause of death worldwide ${ }^{2}$ Although the rate of infectious disease- related deaths has decreased dramatically over the past 20 years, the absolute numbers of such deaths have remained relatively constant, totaling just over 12 million in $2010^{3}$ The World Health Organization estimates that $25 \%$ of the total annual deaths which occur worldwide are caused by microbes, with this 
proportion being significantly higher in the developing world. ${ }^{3}$ Insects such as mosquito and flies are the most common disease vectors and they may carry a parasite, bacteria or virus, infectious to humans and animals. The NVBDCP (National Vector Borne Disease Control Programme) has been started for the control of these vector borne diseases. ${ }^{4}$ During the course of the disease these patients might develop hypotension, renal failure, hepatic dysfunction and respiratory complications warranting the need for inotropic support, mechanical ventilatory support, blood/blood product transfusion as also prolonged ICU (Intensive Care Unit) stay. Amongst the wide range of endemic infectious diseases, the ones endemic to Western Maharashtra were included in this study viz. Dengue, Malaria, Lymphatic filariasis, Amoebiasis, Cholera, Enteric fever, Swine flu (H1N1), Scrub typhus and Leptospirosis.

\section{MATERIALS METHODS INCLUSION CRITERIA}

1. Patients aged 18 years and above

2. Patients suffering from an infectious endemic disease (endemic to Western Maharashtra) requiring critical care unit management
1. Dengue
2. Malaria
3. Lymphatic filariasis
4. Amoebiasis
5. Cholera
6. Enteric fever
7. Swine flu (H1N1)
8. Leptospirosis
9. Scrub Typhus

TYPE OF STUDY - Prospective, non randomized, cross sectional, observational study with sample size of 50 patients studied from October 2017 to October 2019.

\section{SOURCE OF DATA}

All indoor patients suffering from an endemic infectious disease who are critically ill either on presentation or during the course at this tertiary hospital who require intensive care during this study period

PARAMETERS TO STUDY THE OUTCOME OF THE STUDY

1. Indication for ICU management

2. Evidence of multiple system involvement

3. Common precipitating factor

4. Morbidity

5. Mortality

\section{METHOD OF DATA COLLECTION}

1. Critically ill patients with infectious diseases endemic to Western Maharashtra were included in this study Patients with infectious diseases would be classified as critically ill depending on -

1. Temperature $>38$ degrees Celsius or $<36$ degree Celsius

2. Heart rate $>90$ beats/minute

3. Respiratory rate $>20 /$ minute or $\mathrm{PaCo} 2$ less than $32 \mathrm{~mm} \mathrm{Hg}$

4. Total leucocyte count $>12,000 /$ $\mathrm{mm}^{3}$ or $<4,000 / \mathrm{mm}^{3}$ or more than 10 $\%$ immature neutrophils

2. Patients would be assessed according to

1. Detailed history which includes

- demographic details of the patient name,age,sex,residence

- presentation at ICU admission

2. Clinical examination.

- Special emphasis on nature of the infectious disease and cause

- Evidence of clinical features of shock/bleeding manifestations

3. qSOFA Score at presentation

4. SOFA ( Sequential Organ Failure Score Assessment ) score at 24 hours of presentation

5. Course in hospital - Evidence of blood transfusions/ dialysis /ventilatory support/ ionotropic support

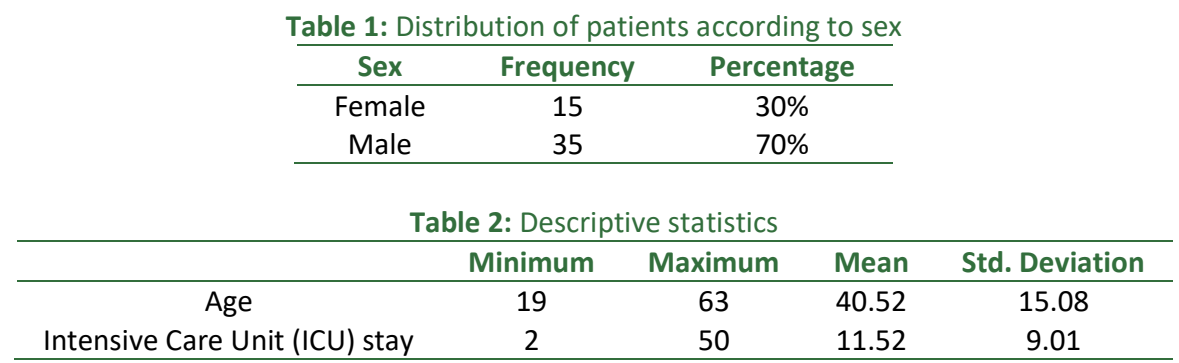

The mean age in our study was $40.52 \pm 15.08$ years with minimum of 19 years and maximum of 63 years. 


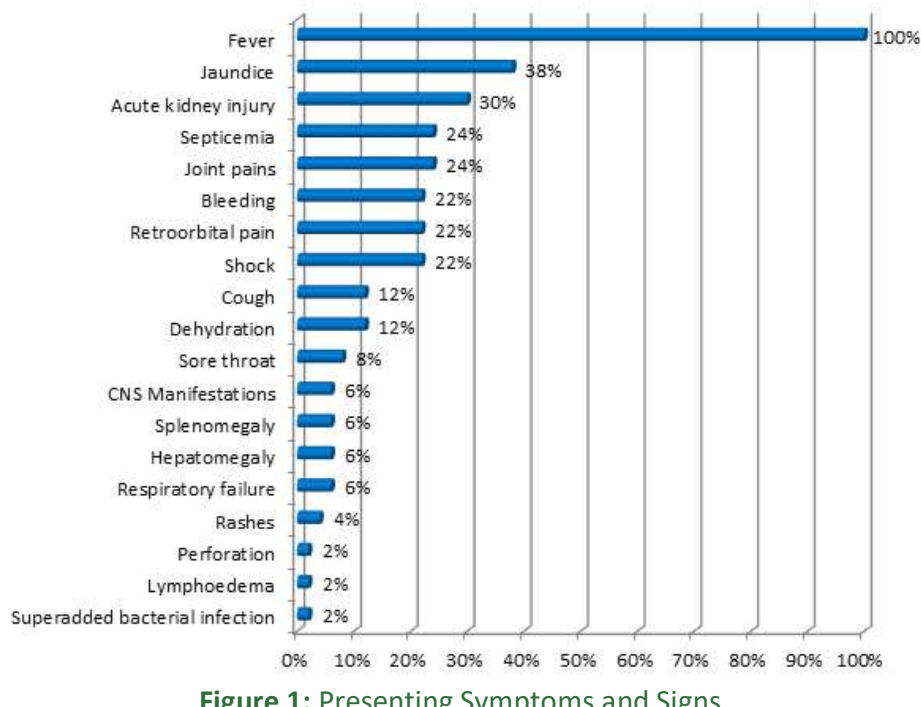

Fever was the most common presenting symptom seen in all 50 cases (100\%) followed by jaundice in 19 cases $(38 \%)$, renal failure in 15 cases (30\%), septicemia and joint pains in 12 patients each (24\%), bleeding and shock in 11 patients each $(22 \%)$ and others.

Table 3: qSOFA score at presentation

\begin{tabular}{ccc}
\hline qSOFA Score & Frequency & Percent \\
\hline 1 & 4 & $8 \%$ \\
2 & 23 & $46 \%$ \\
3 & 23 & $46 \%$ \\
\hline Total & 50 & $100 \%$ \\
\hline
\end{tabular}

qSOFA Score of 2 and 3 were common on presentation, seen in 23 patients each (46\%). While a score of 1 was seen in 4 patients $(8 \%)$ who had abnormalities in their biochemical profile, thus requiring close monitoring.

Table 4: SOFA score after 24 hours of presentation

\begin{tabular}{cc} 
SOFA Score after 24 hours of presentation & $\begin{array}{c}\text { Number of } \\
\text { patients }\end{array}$ \\
\hline 0 to 8 & 11 \\
9 to 16 & 25 \\
17 to 24 & 14 \\
\hline
\end{tabular}

Mean SOFA score at presentation for patients admitted in the ICU for management of endemic infectious diseases was $13.6 \pm 5.3$. Maximum sofa score was 23. Mean SOFA score in patients who did not survive was $21.4 \pm 0.93$. Mean SOFA score in discharged patients was $11.24 \pm 3.3$.

\begin{tabular}{|c|c|c|}
\hline $\begin{array}{l}\text { Hospital Stay for Discharged } \\
\text { patients in days }\end{array}$ & $\begin{array}{l}\text { Average SOFA score after } 24 \text { hours of } \\
\text { admission in Discharged patients }\end{array}$ & $\begin{array}{l}\text { Number of } \\
\text { patients }\end{array}$ \\
\hline 0 to 7 & 8.6 & 12 \\
\hline 8 to 14 & 11.1 & 19 \\
\hline 15 to 21 & 12.2 & 5 \\
\hline 22 to 28 & 12 & 1 \\
\hline 29 to 35 & 16 & 1 \\
\hline 36 and above & 17 & 1 \\
\hline
\end{tabular}

It has been seen that higher SOFA scores at 24 hours of presentation led to longer duration of hospital stay. 
Table 6: Organ failure during the course of ICU stay

\begin{tabular}{ccc}
\hline & Frequency & Percentage \\
\hline Renal & 29 & $58 \%$ \\
Hepatic & 17 & $34 \%$ \\
Haemorrhagic & 14 & $28 \%$ \\
Respiratory & 12 & $24 \%$ \\
CNS & 11 & $22 \%$ \\
\hline
\end{tabular}

Most common organ failure was renal failure in 29 patients (28\%) followed by hepatic failure in 17 patients (34\%) during the course of ICU stay.

Table 7: Co morbidities in the study population

\begin{tabular}{ccc}
\hline & Frequency & Percentage \\
\hline No & 27 & $54 \%$ \\
Yes & 23 & $46 \%$ \\
\hline Total & 50 & $100 \%$ \\
\hline
\end{tabular}

23 patients $(46 \%)$ had co morbidities in our study population.

Table 8: Co morbidities observed in patients in our study

\begin{tabular}{ccc}
\hline & Frequency & Percentage \\
\hline Diabetes & 10 & $20 \%$ \\
Thyroid disorders & 5 & $10 \%$ \\
Chronic liver disease & 3 & $6 \%$ \\
Chronic kidney disease & 2 & $4 \%$ \\
Hypertension & 2 & $4 \%$ \\
Chronic Obstructive Pulmonary Disease & 1 & $2 \%$ \\
None & 27 & $54 \%$ \\
\hline Total & 50 & $100 \%$ \\
\hline
\end{tabular}

Most common co morbidity seen was diabetes in 10 patients (205) followed by thyroid disorders in 5 cases (10\%), Chronic Liver Disease (CLD) in 3 cases (6\%).

Table 9: Requirement of Inotropic support during the course of ICU stay

\begin{tabular}{ccc}
\hline & Frequency & Percentage \\
\hline No & 19 & $38 \%$ \\
Yes & 31 & $62 \%$ \\
\hline Total & 50 & $100 \%$ \\
\hline
\end{tabular}

31 patients $(62 \%)$ required inotropic support during the course of ICU stay.

Table 10: Requirement of mechanical ventilatory support during the course of ICU stay

\begin{tabular}{ccc}
\hline & Frequency & Percentage \\
\hline No & 24 & $48 \%$ \\
Yes & 26 & $52 \%$ \\
\hline Total & 50 & $100 \%$ \\
\hline
\end{tabular}

26 patients $(52 \%)$ required mechanical ventilatory support during the course of ICU stay.

\begin{tabular}{l} 
Table 11: Requirement of haemodialysis during the course of ICU stay \\
\cline { 2 - 3 } \\
\cline { 2 - 3 }
\end{tabular}

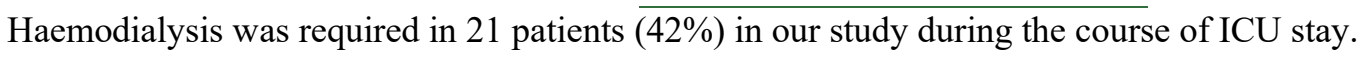

Table 12: Frequency of Diagnosis

\begin{tabular}{ccc}
\hline & Frequency & Percentage \\
\hline Dengue & 15 & $30 \%$ \\
Malaria & 8 & $16 \%$ \\
Leptospirosis & 7 & $14 \%$ \\
Swine Flu & 6 & $12 \%$ \\
Enteric fever & 4 & $8 \%$ \\
Cholera & 4 & $8 \%$ \\
\hline
\end{tabular}




\begin{tabular}{ccc}
\hline Amoebiasis & 3 & $6 \%$ \\
Scrub typhus & 2 & $4 \%$ \\
Lymphatic Filariasis & 1 & $2 \%$ \\
\hline Total & 50 & $100 \%$ \\
\hline
\end{tabular}

The majority of the patients (30\%) in our study were diagnosed with dengue, followed by malaria in 8 patients (16\%), leptospirosis in 7 patients (14\%), swine flu in 6 patients $(12 \%)$, enteric fever in 4 patients (8\%), cholera in 4 patients $(8 \%)$, amoebiasis in 3 patients $(6 \%)$, scrub typhus in $2(4 \%)$ and lymphatic filariasis in 1 patient $(2 \%)$

\begin{tabular}{ccc} 
Table 13: Outcome of patients in the study group \\
\hline & Frequency & Percentage \\
\hline Discharged & 38 & $76 \%$ \\
Total & 50 & $100 \%$ \\
\hline Death & 12 & $24 \%$
\end{tabular}

12 patients in our study died (24\%), while rest 38 patients (76\%) survived and were discharged.

Table 14: Association between outcome and age group of the patient

\begin{tabular}{|c|c|c|c|c|c|}
\hline & & \multicolumn{3}{|c|}{ Age Groups } & Total \\
\hline & & $<30$ & $>50$ & $30-50$ & \\
\hline \multirow[t]{3}{*}{ Outcome } & Death & 3 & 6 & 3 & 12 \\
\hline & Discharged & 16 & 8 & 14 & 38 \\
\hline & & 19 & 14 & 17 & 50 \\
\hline
\end{tabular}

There was no significant association between the outcome and age group of the patient $(p=0.15)$.

Table 15: Association between outcome of the patient and qSOFA score at presentation

\begin{tabular}{|c|c|c|c|c|c|}
\hline & & \multicolumn{3}{|c|}{ qSOFA Score } & Total \\
\hline \multirow{3}{*}{ Outcome } & \multirow{3}{*}{$\begin{array}{c}\text { Death } \\
\text { Discharged }\end{array}$} & 1 & 2 & 3 & \\
\hline & & 0 & 2 & 10 & 12 \\
\hline & & 4 & 21 & 13 & 38 \\
\hline & tal & 4 & 4 & 23 & 50 \\
\hline
\end{tabular}

There was significant association between the outcome of the patient and qSOFA Score at presentation $(p=0.011)$.

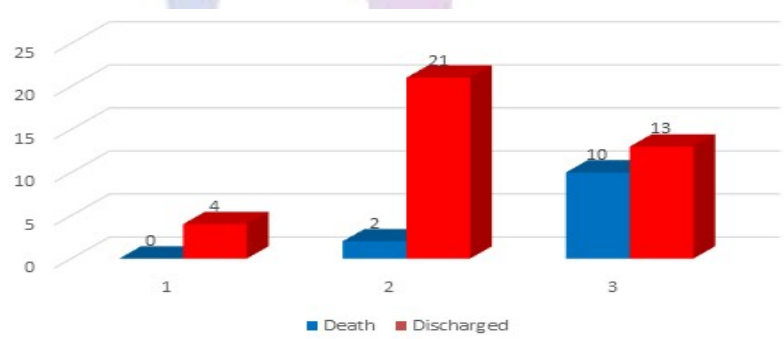

Figure 2: Association between outcome and qSOFA score

Table 16: Association between outcome of the patient and bleeding manifestation

\begin{tabular}{lllll}
\hline & & \multicolumn{2}{l}{$\begin{array}{l}\text { Bleeding } \\
\text { manifestation }\end{array}$} & Total \\
\cline { 3 - 5 } & & No & Yes \\
\hline \multirow{2}{*}{ Outcome } & Death & 7 & 5 & 12 \\
& Discharged & 34 & 4 & 38 \\
\hline Total & & 41 & 9 & 50 \\
\hline & & $\mathrm{X}^{2}=5.99 \mathrm{p}=0.014$ & Significant
\end{tabular}

There was significant association between the outcome and bleeding manifestations in the patients $(p=0.014)$.

Out of 12 patients who had died in our study, 5 had bleeding manifestations (41.67\%), while out of 38 patients who have been treated and discharged, only 4 had bleeding manifestations $(10.53 \%)$. 
Table 17: Association between outcome of the patient and renal failure

\begin{tabular}{ccccc}
\hline \multirow{2}{*}{ Outcome } & \multicolumn{3}{c}{ Renal Failure } & Total \\
\cline { 3 - 5 } & Do & Yes & \\
\cline { 2 - 5 } & Discharged & 30 & 7 & 12 \\
& Total & 35 & 15 & 38 \\
\hline \multicolumn{2}{c}{ Toth } & $\mathrm{X}^{2}=6.04 \mathrm{p}=0.014$ Significant
\end{tabular}

There was significant association between the presence of renal failure and outcome in our study ( $\mathrm{p}=0.014) .7$ out of 12 patients who died had renal failure while 5 did not have it.

Table 18: Association between outcome of the patient and shock

\begin{tabular}{ccccc}
\hline \multirow{2}{*}{ Outcome } & \multicolumn{3}{c}{ Shock } & Total \\
\cline { 3 - 5 } & No & Yes & \\
\hline & Death & 7 & 5 & 12 \\
& Discharged & 32 & 6 & 38 \\
\hline \multicolumn{2}{c}{ Total } & 39 & 11 & 50 \\
\hline \multicolumn{2}{c}{$\mathrm{X}^{2}=3.56 \mathrm{p}=0.06$} & Not Significant &
\end{tabular}

There was no significant association between the outcome of the patients and shock $(\mathrm{p}=0.06)$.

Table 19: Association between outcome of the patient and their co morbidities

\begin{tabular}{ccccc}
\hline \multirow{2}{*}{ Outcome } & \multicolumn{3}{c}{ Co Morbidities } & Total \\
\cline { 3 - 5 } & No & Yes & \\
\hline & Death & 5 & 7 & 12 \\
& Discharged & 22 & 16 & 38 \\
\hline \multicolumn{2}{c}{ Total } & 27 & 23 & 50 \\
\hline \multicolumn{2}{c}{$\mathrm{X}^{2}=0.97 \mathrm{p}=0.33$ Not Significant }
\end{tabular}

There was no significant association between the outcome of the patient and their co morbidities $(p=0.33)$.

Table 20: Association between outcome of the patient and requirement of haemodialysis

\begin{tabular}{ccccc}
\hline \multirow{2}{*}{ Outcome } & \multicolumn{3}{c}{ Co Morbidities } & Total \\
\cline { 3 - 5 } & & No & Yes & \\
\cline { 3 - 5 } & Death & 3 & 9 & 12 \\
& Discharged & 26 & 12 & 38 \\
\hline \multicolumn{2}{c}{ Total } & 29 & 21 & 50 \\
\hline \multicolumn{2}{c}{$\mathrm{X}^{2}=7.06 \mathrm{p}=0.008$ Significant }
\end{tabular}

Out of 12 patients who died, 9 patients received dialysis, while rest 3 did not require it. While out of 38 patients who recovered and discharged, only 12 required dialysis and rest 26 did not require it. There was significant association between the requirement of dialysis and outcome. $(\mathrm{p}=0.008)$

Table 21: Association between diagnosis and outcome of the patient

\begin{tabular}{|c|c|c|c|c|}
\hline & & \multicolumn{2}{|c|}{ Outcome } & \multirow[t]{2}{*}{ Tota } \\
\hline & & Death & Discharged & \\
\hline \multirow[t]{10}{*}{ Diagnosis } & Cholera & 1 & 3 & 4 \\
\hline & Dengue & 5 & 10 & 15 \\
\hline & Enteric fever & 1 & 3 & 4 \\
\hline & Amoebiasis & 0 & 3 & 3 \\
\hline & Leptospirosis & 2 & 5 & 7 \\
\hline & $\begin{array}{l}\text { Lymphatic } \\
\text { Filariasis }\end{array}$ & 0 & 1 & 1 \\
\hline & Malaria & 0 & 8 & 8 \\
\hline & Scrub typhus & 1 & 1 & 2 \\
\hline & Swine Flu & 2 & 4 & 6 \\
\hline & & 12 & 38 & 50 \\
\hline
\end{tabular}


No significant association was seen between the diagnosis and outcome of the patient. $(\mathrm{p}=0.69)$

The deaths observed in the patients according to the infections were

5 out of 15 patients of Dengue died (33.33\%).

2 out of 4 patients of Swine flu died $(50 \%)$.

2 out of 5 patients of Leptospirosis died (40\%).

One each out of 3 cholera and 3 Enteric Fever patients died (33.33\% each).

There was one patient of scrub typhus who died (100\%) due to septic shock.

\section{DISCUSSION}

We studied 50 patients of locally endemic infectious diseases admitted in the Intensive Care Unit of our tertiary care hospital and medical college. Many studies have described a single endemic disease. In our study we are including patients from nine endemic diseases which satisfied our study selection criteria. Tthere were 15 females $(30 \%)$ and 35 males $(70 \%)$. Male to female ratio was $2.33: 1$. Juneja $\mathrm{D}$ et al. in their study had $61.1 \%$ males and Sivarajan S et al. had $52.2 \%$ males, which was comparable to our study. 5,6 Table number 2 of our study showed that the Intensive Care Unit (ICU) stay duration was $11.52 \pm 9.01$ days with a minimum of 2 and a maximum of 50 days. Longest ICU stay in this study has been seen in a patient of dengue shock syndrome. While the study of Kartik Ramakrishna et al. revealed that the required ICU admission stay was $5.8 \pm 2.7$ days. $^{7}$ The mean age in our study was $40.52 \pm 15.08$ years with a minimum of 19 years and maximum of 63 years. The most common presenting symptom was fever in all 50 cases $(100 \%)$ as seen in table number 4 followed by jaundice in 19 cases (38\%), acute kidney injury in 15 cases $(30 \%)$, septicemia and joint pains in 12 patients each (24\%), bleeding, shock and retro orbital pain in 11 patients each $(22 \%)$ followed by other symptoms. The study by Ambika Sharma revealed that patients of H1N1 commonly presented with symptoms of cough and fever (95\%). Most common findings were increased temperature, tachycardia, tachypnea and crepitation on auscultation. ${ }^{8}$ The study by Frederico Figueiredo Amâncio showed the most common presentation as shock (22.7\%) followed by severe thrombocytopenia with or without minor bleeding and respiratory failure. These were the main causes of ICU admission in dengue patients. Hemorrhagic manifestations were seen in $73.2 \%$ patients such as petechiae, ecchymosis and suffusion. Other bleeding manifestations such as mucosal bleeding, gum bleeding, epistaxis and hematuria were also noted. Fever and myalgia were the other common symptoms. ${ }^{9}$ Sivarajan $\mathrm{S}$ et al. reported that fever of $<7$ days $(83.3 \%)$ was the most common presentation followed by myalgia, pain abdomen, headache, nausea/vomiting, dry cough, hepatomegaly, splenomegaly and lymphadenopathy as the other predominant clinical features amongst their patients. ${ }^{6}$ Our study showed that qSOFA score of 2 or more than 2 at presentation was common. This was seen in 23 patients each $(46 \%)$ while score of 1 was seen in 4 patients $(8 \%)$, who had abnormalities in their biochemical profile, thus requiring close monitoring. Kartik Ramakrishna et al. in his study details the profile and outcomes of patients admitted to the intensive care unit (ICU) with pandemic Influenza A (H1N1). Sequential organ failure assessment (SOFA) scores were calculated daily. ${ }^{7}$ SOFA score at 24 hours of presentation showed that mean SOFA score at presentation for patients admitted in the ICU for management of endemic infectious diseases was $13.6 \pm 5.3$. Maximum SOFA score was 23.Mean SOFA score in patients who did not survive was $21.4 \pm 0.9$ while mean SOFA score in discharged patients was $11.24 \pm 3.3$. Higher SOFA scores at 24 hours of presentation led to longer duration of hospital stay. Most patients in our setup had a ICU stay extending into the second week. The most common organ failure during the course of the ICU stay was renal failure in 29 patients $(28 \%)$ followed by hepatic failure in 17 patients (34\%) and respiratory failure seen in 12 patients (24\%). Sivarajan S et al. reported one third of the patients developed at least one systemic complication. Acute hepatitis $(16.7 \%)$, followed by pneumonitis, and acute kidney injury were the common complications. ${ }^{6}$ Ambika et $a l$. study revealed that consolidation was seen in nearly half of the patients on radiological imaging. Complications noted in their patients were pneumonia (45\%), followed by respiratory failure and ARDS. ${ }^{8}$ Juneja D et al. in their study on dengue patients found $13.1 \%$ cases had respiratory failure. ${ }^{5}$ Ramesh Holla et al. study showed acute renal failure as the most common complication at $79.2 \% .{ }^{10} 23$ patients (46\%) had comorbidities in our study. Arunkumar et al. study showed that $35 \%$ had co-morbid condition with the influenza A H1N1 disease. Their study found that in patients with associated comorbid conditions, $84 \%$ were discharged. Mortality was $16 \%$ among patients with co morbidity. ${ }^{11}$ Anish Gupta et al. in their study found that fifty-one patients had underlying comorbidities. ${ }^{12}$

The most common co morbidity was diabetes in 10 patients (20\%) followed by thyroid disorders in 5 cases $(10 \%)$, Chronic Liver Disease (CLD) in 3 cases (6\%) followed by chronic kidney disease and hypertension. There were no comorbidities in 27 patients (54\%). Ambika Sharma et al. study depicted that the associated comorbidities were Diabetes mellitus (19.5\%), chronic kidney disease $(17 \%)$ and immunosuppression $(9.8 \%){ }^{8}$ Majority of the patients -15 patients had dengue ( $30 \%$ ), followed by malaria in 8 patients $(16 \%)$, leptospirosis in 7 patients (14\%), swine flu in 6 patients $(12 \%)$, enteric fever 
in 4 patients $(8 \%)$, cholera in 4 patients $(8 \%)$, amoebiasis in 3 patients $(6 \%)$, scrub typhus in $2(4 \%)$ and lymphatic filariasis in 1 patient $(2 \%)$. According to the outcome, 38 patients $(76 \%)$ survived while 12 patients in our study died (24\%). Mortality rate in the study by FredericoFigueiredoAmâncio was $18.6 \%$ and $19.6 \%$ in ICU and hospital respectively. ${ }^{9}$ There was significant association between the poor outcome of the patients and higher qSOFA score $(\mathrm{p}=0.011)$ at presentation. Poor outcome was noted in patients who presented with a qSOFA score of 2 or more. A total number of 12 deaths were reported in our study of which 10 patients had a qSOFA score of 3 . Amongst the 38 patients who were discharged in our study, 25 patients presented with a qSOFA score of 1 or 2 while 13 patients presented with a qSOFA score of 3 . There was a significant association between the occurrence of renal failure and poor outcome in our study $(\mathrm{p}=0.014)$. Of the 12 patients who succumbed, 7 patients had renal failure, whereas of the 38 patients who survived 8 had renal failure. Kartik Ramakrishna et al. in his study concluded that need for dialysis was independently associated with mortality $(P=0.019){ }^{7}$ Sivarajan $\mathrm{S}$ et al. also reported significant association between the renal failure and multi organ failure with outcome in terms of mortality. ${ }^{6}$ The mean age and mean duration of ICU stay were not showing any significant difference in outcome of the disease $(p>0.05)$. There was no significant association between the diagnosis and outcome of the patients. $(\mathrm{p}=0.69)$. The deaths observed in patients according to the infections were as follows:

\section{CONCLUSION}

Endemic infectious diseases in the study had varied clinical presentation. The course in the Intensive Care Unit (ICU) was often complicated by multisystem involvement and organ failure. SOFA score more than 20 at 24 hours of presentation was associated with higher mortality rate. qSOFA score of 2 or above at the time of hospitalisation was an important predictor of mortality. Other associated factors were bleeding manifestations, acute kidney injury, hypotension requiring inotropic support and respiratory compromise requiring mechanical ventilation. Understanding these clinical features and complications will help to identify patients at high risk and treat them with optimal intensive care to reduce mortality.

\section{REFERENCES}

1. Balfour A Some British and American pioneers in tropical medicine and hygiene Trans R Soc Trop Med Hyg 1925

2. Fauci AS, Touchette NA, Folkers GK. Emerging Infectious Diseases: a 10-Year Perspective from the National Institute of Allergy and Infectious Diseases. Emerging Infectious Diseases 2005;11:519-25.

3. WHO. Research priorities in communicable diseases. Report of a regional meeting WHO/SEARO,New Delhi. 2010.

4. DGHS. Directorate General Of Health Services. https://dghs.gov.in/content/1364_3_NationalVectorBorne DiseaseControlProgramme.aspx (accessed December 6, 2019).

5. Juneja D, Nasa P, Singh O, Javeri Y, Uniyal B, Dang R. Clinical profile, intensive care unit course, and outcome of patients admitted in intensive care unit with dengue.J Crit Care. 2011 Oct;26(5):449-452

6. Sivarajan S, Shivalli S, Bhuyan D, Mawlong M, Barman R. Clinical and paraclinical profile, and predictors of outcome in 90 cases of scrub typhus, Meghalaya, India.Infect Dis Poverty. 2016 Oct 5;5(1):91.

7. Ramakrishna K, Sampath S, Chacko J, et al. Clinical Profile and Predictors of Mortality of Severe Pandemic (H1N1) 2009 Virus Infection Needing Intensive Care: A Multi-Centre Prospective Study from South India. J Glob Infect Dis. 2012;4(3):145-152.

8. Ambika Sharma, R. S. Mathur et al. Clinical profile and outcome of patients admitted with swine-origin Influenza A H1N1 virus infection at a tertiary care hospital in Western India - volume 6 number 4, 2019

9. Amâncio FF, Heringer TP, Oliveira CdCHBd, Fassy LB, CarvalhoFBd, Oliveira DP, et al.. (2015) Clinical Profiles and Factors Associated with Death in Adults with Dengue Admitted to Intensive Care Units, Minas Gerais, Brazil. PLoS ONE 10(6): e0129046

10. Ramesh Holla et al.. Leptospirosis in Coastal South India: A Facility Based Study, BioMed Research International Volume 2018, Article ID 1759125

11. Arunkumar Ishwarbhai Chaudhari, Jitendra R Zaveri, NileshThakorProfile of confirmed H1N1 virus infected patients admitted in the swine flu isolation ward of tertiary care hospitals of Baroda district, Gujarat, India volume 3, number 9, 2015

12. Gupta A, Juneja D, Singh O, Garg SK, Arora V, Deepak D. Clinical Profile, Intensive Care Unit Course, and Outcome of Patients Admitted in Intensive Care Unit with Chikungunya. Indian J Crit Care Med. 2018;22(1):5-9.

13. Cook GC Tropical medicine - An illustrated history of pioneers London Academic press 2007.

14. Harrison M. A Global Perspective: Reframing the History of Health, Medicine, and Disease. Bulletin of the History of Medicine 2015;89:639-89.

15. Baradari A, Firouzian A, Davanlou A, Aarabi M, Daneshiyan M, Kiakolaye A. Comparison of Patients Admission, Mean and Highest Sofa Scores in Prediction of ICU Mortality: a Prospective Observational Study. Materia Socio Medica 2016;28:343.

\section{Source of Support: None Declared Conflict of Interest: None Declared}

